\title{
Dissociation and fantasy proneness in psychiatric patients: a preliminary study
}

Citation for published version (APA):

Merckelbach, H. L. G. J., a Campo, J. M. L. G., Hardy, S., \& Giesbrecht, T. M. (2005). Dissociation and fantasy proneness in psychiatric patients: a preliminary study. Comprehensive Psychiatry, 46, 181-185. https://doi.org/10.1016/j.comppsych.2004.08.001

Document status and date:

Published: 01/01/2005

DOI:

10.1016/j.comppsych.2004.08.001

Document Version:

Publisher's PDF, also known as Version of record

\section{Please check the document version of this publication:}

- A submitted manuscript is the version of the article upon submission and before peer-review. There can be important differences between the submitted version and the official published version of record.

People interested in the research are advised to contact the author for the final version of the publication, or visit the DOI to the publisher's website.

- The final author version and the galley proof are versions of the publication after peer review.

- The final published version features the final layout of the paper including the volume, issue and page numbers.

Link to publication

\footnotetext{
General rights rights.

- You may freely distribute the URL identifying the publication in the public portal. please follow below link for the End User Agreement:

www.umlib.nl/taverne-license

Take down policy

If you believe that this document breaches copyright please contact us at:

repository@maastrichtuniversity.nl

providing details and we will investigate your claim.
}

Copyright and moral rights for the publications made accessible in the public portal are retained by the authors and/or other copyright owners and it is a condition of accessing publications that users recognise and abide by the legal requirements associated with these

- Users may download and print one copy of any publication from the public portal for the purpose of private study or research.

- You may not further distribute the material or use it for any profit-making activity or commercial gain

If the publication is distributed under the terms of Article $25 \mathrm{fa}$ of the Dutch Copyright Act, indicated by the "Taverne" license above, 


\title{
Dissociation and fantasy proneness in psychiatric patients: a preliminary study
}

\author{
Harald Merckelbach*, Joost à Campo, Solange Hardy, Timo Giesbrecht \\ Department of Experimental Psychology, University of Maastricht, 6200 MD, Maastricht, The Netherlands \\ Faculty of Law, University of Maastricht, 6200 MD, Maastricht, The Netherlands \\ Psychiatric Hospital, Mondriaan Zorggroep, Heerlen, The Netherlands
}

\begin{abstract}
Nonclinical studies found that dissociative experiences are intimately linked to a trait known as fantasy proneness. We examined the links among dissociative symptoms, fantasy proneness, and impulsivity in psychiatric outpatients. Our sample consisted of 22 patients with schizophrenia, 20 patients with a diagnosis of borderline personality disorder, and 19 patients with a major depressive disorder. For the whole sample, levels of dissociation were found to be related to fantasy proneness and impulsivity. There were group differences in dissociative symptoms, with patients with borderline personality disorder reporting more such symptoms than patients with either schizophrenia or major depressive disorder. The overlap between dissociation and fantasy proneness may have important ramifications for studies addressing comorbid phenomena of dissociative symptoms.
\end{abstract}

(C) 2005 Published by Elsevier Inc.

\section{Introduction}

Dissociative symptoms, such as derealization, depersonalization, and amnesia, have attracted widespread attention in recent years. Clinical literature often emphasizes the close connection between dissociative symptoms and childhood trauma. Accordingly, trauma-oriented interpretations of dissociative symptoms dominate this literature $[1,2]$. However, apart from clinical studies on dissociative symptoms, recent work has focused on traitlike manifestations of dissociation and how they might relate to key personality characteristics. One of the best replicable findings in this research line is that dissociation is intimately related to a trait known as fantasy proneness. Since the pioneering work of Wilson and Barber [3], fantasy proneness has come to be used as a label for individuals who exhibit a deep, profound, and longstanding involvement in fantasy and imagery. Fantasy proneness is closely associated with the concept of absorption, and both are often interpreted as manifes-

* Corresponding author. Department of Experimental Psychology, University of Maastricht, PO Box 616, 6200 MD, Maastricht, The Netherlands.

E-mail address: h.merckelbach@psychology.unimaas.nl (H. Merckelbach) tations of the higher order trait "openness to experience" [4]. Research by Lynn and Rhue [5] showed that fantasy proneness is a benign trait and that most fantasizers are relatively well-adjusted people. As to its origins, the moderately high heritability that the twin studies found for openness to experience [6] and absorption [7] suggests that individual differences in fantasy proneness are, at least to some extent, mediated by genetic factors.

The first large-scale study that documented a substantial overlap between dissociative experiences and fantasy proneness was that by Silva and Kirsch [8], who reported for their undergraduate sample a correlation of 0.42 between both constructs. Using a somewhat different approach, Rauschenberger and Lynn [9] and Waldo and Merritt [10] recruited individuals high and low on fantasy proneness from their student samples and compared them with regard to dissociation levels. Both studies concluded that highfantasy-prone students reported significantly more dissociative symptoms than students scoring low or medium on fantasy proneness. Thus, all these studies indicate that dissociation and fantasy proneness define a common domain. Relying on a nonclinical sample of older children and adolescents, Muris et al [11] reported a correlation of 0.65 between dissociation and fantasy proneness. This shows that the overlap between both constructs is not 
restricted to adult samples only, but can also be found earlier in the developmental pathway.

So far, only one clinical study looked at the link between dissociation and fantasy proneness [12]. In that study, a large sample of male patients with substance abuse were administered self-report measures of dissociation, fantasy proneness, and childhood trauma. Replicating the results of nonclinical studies, the authors found a moderate correlation between dissociation and fantasy proneness $(r=0.41)$.

Several authors noted a connection between fantasy proneness, on the one hand, and reports of bizarre symptoms [13] and overendorsement of trivial autobiographical events [14], on the other hand. This suggests that a positive response tendency is an intrinsic feature of fantasy proneness, putting into question the accuracy of self-reports of fantasy-prone patients. To the extent that dissociation overlaps with fantasy proneness, a similar question can be raised with regard to subjective reports of individuals scoring high on dissociation [15]. Another and theoretically more relevant issue has to do with the mechanism behind the tendency of fantasy-prone patients to overendorse implausible answer options. One possibility is that this biased response tendency originates from impulsivity. To the best of our knowledge, only a study by Steiger et al [16] examined whether impulsivity is linked to dissociation. In a sample of bulimic patients, they found this to be the case.

As little is known about the link between dissociation and fantasy proneness in psychiatric patients, the current study made a first attempt to explore this issue in a sample of outpatients who suffered from severe psychopathology. We also looked at the possible role of impulsivity in the link between dissociation and fantasy proneness. To tap a broad range of psychopathology, we recruited patients with schizophrenia, borderline personality disorder (BPD), and major depressive disorder (MDD).

\section{Method}

\subsection{Patients}

Participants were 61 consecutive outpatients presenting at a follow-up treatment facility of a psychiatric clinic in Heerlen, the Netherlands. Before participating in the study, all patients gave their written informed consent. Twenty-two patients (4 women) fulfilled the criteria of the Diagnostic and Statistical Manual of Mental Disorders, Fourth Edition (DSM-IV) for chronic schizophrenia, 20 patients (12 women) had a DSM-IV diagnosis of BPD, and 19 (7 women) had a $D S M-I V$ diagnosis of either single-episode or recurrent MDD without psychotic features [17]. Clinical diagnoses had been made by a team of senior psychiatrists. All patients were clinically stabilized. Patients with neurological abnormalities were excluded. All patients with schizophrenia were on maintenance neuroleptic medication, whereas the large majority of patients with BPD and MDD were treated with antidepressants and/or mood stabilizers.
Mean (SD) age of the patients was 41.3 (10.7) years, but patients with MDD (47.2 years; SD 10.0) were significantly older than patients with either BPD (38.2 years; SD 8.4) or schizophrenia (38.9 years; $\mathrm{SD} 11.5)\left(\mathrm{F}_{2,58}=4.77, P<.05\right)$.

\subsection{Measures}

Patients filled out the Dissociative Experiences Questionnaire (DES) [18], the Creative Experiences Questionnaire (CEQ) [19], and the Barratt Impulsiveness Scale (BIS11) [20]. The DES is widely used for measuring dissociative phenomena. Examples of such phenomena include disturbances in memory (eg, not sure if remembered event happened or was a dream), perception (eg, hearing voices inside one's head), and awareness (eg, finding oneself in a place but unaware how one got there). The DES contains 28 items that ask for the frequency of such disturbances. An illustrative item is: "Some people find that they sometimes sit staring off into space, thinking of nothing, and are not aware of the passage of time. Mark the line to show what percentage of the time this happens to you." In the current study, patients used 100-mm visual analog scales (anchors, $0=$ not at all; $100=$ very much) to indicate the percentage of time they experienced dissociative phenomena. Scores were averaged across items to obtain a mean DES score, with higher DES scores indicating a higher frequency of dissociative experiences. Waller et al [21] have pointed out that mild dissociative experiences related to absorption and imaginative involvement are quite common in the normal population, whereas a subset of experiences tapping pathological dissociation is rarely found among healthy individuals. These pathological forms of dissociation are represented with 8 items in the DES (ie, DES-T items). After the approach of Eisen and Carlson [22], we calculated a DES-T score by averaging across those 8 DES items that are thought to tap pathological dissociation.

The CEQ is a 25-item yes/no measure of fantasy proneness. Some CEQ items allude to the developmental antecedents of fantasy proneness. Other items are related to intense elaboration of and profound involvement in fantasy and daydreaming. Still others pertain to the concomitants and consequences of fantasizing. Items were derived from the typology of this trait by Wilson and Barber [3]. Sample items are the following: "As a child, I could very easily identify with the main character of a story or movie"; "When I recall my childhood, I have very vivid and lively memories"; and "I can recall many occurrences before the age of three." Yes answers are summed to obtain a total score (range, 0-25), with higher scores indicating higher levels of fantasy proneness. The CEQ possesses adequate reliability in terms of internal consistency and test-retest stability. Furthermore, the CEQ has predictive validity in the sense that certain categories of individuals who are known to exhibit fantasy-prone characteristics (eg, amateur actors) display higher scores on this scale than do control individuals. Finally, the CEQ demonstrates concurrent validity in that it correlates strongly with another index of 
Table 1

Pearson correlations between dissociation measures (DES and DES-T), fantasy proneness (CEQ), and impulsivity (BIS-11) for the whole sample $(\mathrm{N}=61)$

\begin{tabular}{llll}
\hline & DES & DES-T & CEQ \\
\hline DES-T & $0.91^{*}$ & & \\
CEQ & $0.55^{*}$ & $0.48^{*}$ & \\
BIS-11 & $0.32^{*}$ & 0.23 & 0.25 \\
\hline \multicolumn{2}{l}{$P<.05$, 2-tailed. } & &
\end{tabular}

fantasy proneness, namely the Inventory of Childhood Memories and Imaginings. There is no direct overlap in item content between CEQ and DES $[19,23]$.

The BIS-11 is a 30 -item self-report scale designed to measure impulsivity. The scale is widely used in psychiatric research on impulsivity [24]. It contains items such as "I buy things on impulse," "I am a careful thinker," and "I say things without thinking." Items are scored on a 4-point scale (anchors, 1 = rarely; 4 = always), and scores are then summed to obtain a total impulsivity score, with higher scores indicating higher levels of impulsivity.

\subsection{Procedure}

After they had given their informed consent, patients were tested individually in a quiet room at the psychiatric clinic. A research assistant was present for providing clarification when patients had questions. Patients were instructed to complete the scale in their own pace and they were told that the data thus obtained would be treated confidentially.

\section{Results}

Cronbach $\alpha$ 's for DES, DES-T, CEQ, and BIS-11 were $.93, .79, .82$, and .78 , respectively, indicating that internal consistency of our measures was satisfactory. There were no significant sex differences with regard to any of the measures (all $t_{59}$ 's $<1.0$ ). Neither were there significant correlations between age and any of our measures (all $r$ 's $<0.21$, all $P$ 's $>.09,2$-tailed).

Table 1 shows the Pearson product moment correlations among DES, DES-T, CEQ, and BIS-11 for the full sample. As can be seen, both indices of dissociation (ie, DES and DES-T) were significantly related to fantasy proneness (CEQ), with correlations coming close to those that have been reported for nonclinical samples $[8,11,23]$. As well, DES was significantly related to the impulsivity measure (BIS-11). However, correlations between DES-T and CEQ, on the one hand, and BIS-11, on the other hand, remained nonsignificant. A regression analyses indicated that together, fantasy proneness and impulsivity explained 35\% of the variance in DES scores $\left(R=0.59, R^{2}=0.35\right)$.

Table 2 shows the mean scores of the 3 patient groups on the DES, DES-T, CEQ, and BIS-11. A series of 1-way analyses of variance made it clear that there were significant group differences with regard to DES $\left(\mathrm{F}_{2,58}=3.93, P<.05\right)$ and CEQ $\left(\mathrm{F}_{2,58}=4.32, P<.05\right)$, but that group differences in DES-T and BIS-11 fell short of significance (both F's $<1.78$, both $P$ 's $>.18$ ). As for the group differences in DES scores, post hoc least significant difference (LSD) comparisons indicated that patients with BPD had significantly higher dissociation levels than patients with either schizophrenia or MDD, but that dissociation scores of patients with schizophrenia and MDD did not differ at the $P<.05$ level. A similar pattern was found for CEQ, that is, patients with BPD displayed higher scores on the fantasy proneness scale (CEQ) than patients with either schizophrenia or MDD, whereas the latter 2 groups did not differ in this respect. When CEQ was entered as a covariate in an analysis of variance performed on DES scores, group differences in dissociative symptoms disappeared $\left(\mathrm{F}_{2,57}=1.07, P=.35\right)$.

\section{Discussion}

The key finding of this initial study is that the overlap between dissociation and fantasy proneness is not restricted to healthy samples or samples with mild psychopathology [8-12], but it also occurs in individuals with severe psychopathology. Clearly, our data do not indicate whether this overlap can be found in patients with a dissociative disorder, which is an issue that requires further study. However, they do indicate that common dissociative phenomena (as measured by the DES) as well as pathological manifestations of dissociation (as measured by the DES-T) overlap with fantasy proneness. Given the tendency of highfantasy-prone people to overendorse bizarre items [13], the implications of this overlap might be far-reaching. More precisely, our findings suggest that studies relying on selfreports to address comorbid phenomena of dissociation (eg, visual distortions $[25,26]$ ) would be well advised to consider the role of fantasy proneness into account.

As was the case in previous studies [27], we found that patients with BPD are characterized by significantly higher group mean levels of dissociation than are patients with schizophrenia or depression. In clinical literature, such group

Table 2

Mean (SD) scores on dissociation measures (DES and DES-T), fantasy proneness (CEQ), and impulsivity (BIS-11) of patients with schizophrenia, BPD, and MDD

\begin{tabular}{lllll}
\hline Measures & Patients with schizophrenia $(\mathrm{n}=22)$ & Patients with BPD $(\mathrm{n}=20)$ & Patients with MDD $(\mathrm{n}=19)$ & $\mathrm{F}$ \\
\hline DES & $21.5(16.5)$ & $31.0(15.9)$ & $17.8(12.8)$ & 3.9 \\
DES-T & $17.8(18.1)$ & $21.1(16.8)$ & $11.3(14.1)$ & .03 \\
CEQ & $8.4(4.4)$ & $11.8(5.1)$ & $7.6(4.7)$ & .18 \\
BIS-11 & $66.5(11.6)$ & $67.2(10.2)$ & $63.2(7.9)$ & .8 \\
\hline
\end{tabular}


differences in dissociation are often taken to imply that the traumatogenic contribution to the etiology of these disorders must also differ [28]. However, the current study indicates that at least for patients with BPD, schizophrenia, and MDD, group differences in dissociation disappear once one corrects for the influence of fantasy proneness. This suggests that group differences in dissociation not only reflect differences in trauma history, but also temperamental variations [29]. Note that traits closely allied with fantasy proneness, namely, openness to experience and absorption, are known to have a substantial genetic component [6]. In fact, a twin study by Jang et al [30] showed that genetic factors account for about half of the variance in DES scores. Again, this underlines the temperamental dimension of dissociation.

The current study also found a significant, albeit modest correlation between dissociation as indexed by the DES and impulsivity. However, impulsivity was not related to pathological dissociation, nor was it related to fantasy proneness. Thus, our hypothesis that impulsivity and fantasy proneness might define a common domain was not borne out by the data. Perhaps, impulsivity and fantasy proneness function as 2 independent correlates of general dissociation. Meanwhile, our finding that impulsivity is a correlate of dissociative symptoms is important because there are good reasons to suspect that impulsivity goes together with mild executive deficits [31]. The connections among impulsivity, dissociation, and frontally mediated cognition warrant further study. Curiously enough, patients with BPD in our study did not have significantly higher impulsivity scores than patients with either schizophrenia or MDD. Impulsivity is a key feature of BPD, but it is also closely related to substance abuse and some manifestations (eg, suicidality) of depression [24]. Thus, it may well be the case that the presence of concomitant disorders (eg, substance abuse) and characteristics (eg, suicidality) in our patients with schizophrenia and MDD accounts for the lack of group differences in impulsivity.

Our study was a first attempt to address the links among dissociation, fantasy proneness, and impulsivity in patients with severe psychopathology. Our sample size was relatively small, and this might have undermined the statistical power to detect differences in impulsivity between diagnostic groups or correlations between fantasy proneness and impulsivity. At the very least, our results demonstrate that the correlation between dissociation and fantasy proneness is a robust one that can be easily replicated in a heterogeneous group of psychiatric patients. This finding is only a starting point for large-scale clinical studies that may ultimately uncover the origins of normal and abnormal dissociation.

\section{References}

[1] Gast U, Rodewald F, Nickel V, Emerich HM. Prevalence of dissociative disorders among psychiatric inpatients in a German university clinic. J Nerv Ment Dis 2001;189:249-57.
[2] Gershuny BS, Thayer JF. Relations among psychological trauma, dissociative phenomena, and trauma-related distress: a review and integration. Clin Psychol Rev 1999;19:631-57.

[3] Wilson SC, Barber TX. Fantasy-prone personality: implications for understanding imagery, hypnosis, and parapsychological phenomena. In: Sheikh AA, editor. Imagery: current theory, research, and application. New York: Wiley; 1983. p. 340-87.

[4] Kihlstrom JF, Glisky ML, Angiulo MJ. Dissociative tendencies and dissociative disorders. J Abnorm Psychol 1994;103:117-24.

[5] Lynn SJ, Rhue JW. Fantasy proneness: hypnosis, developmental antecedents, and psychopathology. Am Psychol 1988;43:35-44.

[6] Bergeman CS, Chipuer HM, Plomin R, Pedersen NL, McClearn GE, Nesselroade JR, et al. Genetic and environmental effects on openness to experience, agreeableness, and conscientiousness: an adoption/twin study. J Pers 1993;61:159-79.

[7] Tellegen A, Lykken DT, Bouchard TJ, Wilcox KJ, Segal NL, Rich S. Personality similarity in twins reared apart and together. J Pers Soc Psychol 1988;54:1031-9.

[8] Silva CE, Kirsch I. Interpretive sets, expectancy, fantasy proneness, and dissociation as predictors of hypnotic response. J Pers Soc Psychol 1992;63:847-56.

[9] Rauschenberger SL, Lynn SJ. Fantasy proneness, DSM-III-R Axis I psychopathology, and dissociation. J Abnorm Psychol 1995;104: $373-80$.

[10] Waldo TG, Merritt RD. Fantasy proneness, dissociation, and DSM-IV Axis II symptomatology. J Abnorm Psychol 2000;109:555-8.

[11] Muris P, Merckelbach H, Peeters E. The links between the Adolescent Dissociative Experiences Scale (A-DES), fantasy proneness, and anxiety symptoms. J Nerv Ment Dis 2003;191:18-24.

[12] Pekala RJ, Kumar VK, Ainslie G, Elliott NC, Mullen KJ, Salinger $\mathrm{MM}$, et al. Dissociation as a function of child abuse and fantasy proneness in a substance abuse population. Imagin Cogn Pers 2000;19:105-29.

[13] Merckelbach H, Smith GP. Diagnostic Accuracy of the Structured Inventory of Malingered Symptomatology (SIMS) in detecting instructed malingering. Arch Clin Neuropsychol 2003;18:145-52.

[14] Johnson RC, Edman JL, Danko GP. Self reported negative experiences and dissociation. Pers Individ Differ 1995;18:793-5.

[15] Candel I, Merckelbach H. Peritraumatic dissociation as a predictor of post-traumatic stress disorder: a critical review. Compr Psychiatry 2004; $45: 44-50$.

[16] Steiger H, Leonard S, Kin NY, Ladoucer C, Ramdoyal D, Young SN. Childhood abuse and platelet tritiated-paroxetine binding in bulimia nervosa: implications of borderline personality disorder. J Clin Psychiatry 2000;61:428-35.

[17] American Psychiatric Association. Diagnostic and statistical manual of mental disorders (DSM-IV). 4th ed. Washington (DC): American Psychiatric Association; 1994.

[18] Bernstein EM, Putnam FW. Development, reliability, and validity of a dissociation scale. J Nerv Ment Dis 1986;174:727-35.

[19] Merckelbach H, Horselenberg R, Muris P. The Creative Experiences Questionnaire (CEQ): a brief self-report measure of fantasy proneness. Pers Individ Differ 2001;31:987-95.

[20] Patton JH, Stanford MS, Barratt ES. Factor structure of the Barratt Impulsiveness Scale. J Clin Psychol 1995;51:768-74.

[21] Waller NG, Putnam FW, Carlson EB. Types of dissociation and dissociative types: a taxometric analysis of dissociative experiences. Psychol Methods 1996;1:300-21.

[22] Eisen ML, Carlson EB. Individual differences in suggestibility: examining the influence of dissociation, absorption, and a history of childhood abuse. Appl Cogn Psychol 1998;12:47-61.

[23] Merckelbach H, Horselenberg R, Schmid H. Modeling the connection between self-reported trauma and dissociation in a student sample. Pers Individ Differ 2002;32:695-705.

[24] Moeller FG, Barratt ES, Doughery DM, Schmitz JM, Swann AC. Psychiatric aspects of impulsivity. Am J Psychiatry 2001;158: 1783-93. 
[25] Merckelbach H, Jelicic M. Dissociative symptoms are related to endorsement of vague trauma items. Compr Psychiatry 2004;45:70 - 5 .

[26] Lipsanen T, Lauerma H, Peltola P, Kallio S. Visual distortions and dissociation. J Nerv Ment Dis 1999;187:109-12.

[27] Putnam FW, Carlson EB, Ross CA, Anderson G, Clark P, Torem M, et al. Patterns of dissociation in clinical and nonclinical samples. J Nerv Ment Dis 1996;184:673 - 9 .

[28] Ross CA. Dissociative identity disorder: diagnosis, clinical features, and treatment of multiple personality. New York: Wiley; 1997.
[29] Zanarini MC, Ruser T, Frankenburg FR, Hennen J, Gunderson JG. Risk factors associated with the dissociative experiences of borderline patients. J Nerv Ment Dis 2000;188:26-30.

[30] Jang KL, Paris J, Zweig-Frank H, Livesley WJ. Twin study of dissociative experiences. J Nerv Ment Dis 1998;186:345-51.

[31] Dowson J, Bazanis E, Rogers R, Prevost A, Taylor P, Meux C, et al. Impulsivity in patients with borderline personality disorder. Compr Psychiatry 2004;45:29-36. 